\title{
Shamanism and folk music as ethnosurvival factors
}

\section{About the Ostyaks in general}

The Ugrian branch of the Finno-Ugrian language family consists of three languages: Ostyak (Khanty), Vogul (Mansi) and Hungarian (Magyar). This means that Ostyaks and Voguls, i.e. the Ob-Ugrians are the closest language relatives of the Hungarians. All those three peoples have their inner names, their ethnonym (in brackets), and their outer names, those by which other nations call them. In the case of Hungarians this does not present a problem, but in the case of Voguls and Ostyaks it is difficult to find out which name we should use, as some groups of Ostyaks, for example, feel it humiliating or contemptuous to be called Ostyaks. For a while we also used their ethnonyms in publications. But now for various reasons some researchers have decided to use the outer names: this is customary in the case of other peoples; it was customary in earlier publications in German and English, and last but not least, the ethnonym of the Ostyaks sounds different in different dialects.

The Ob-Ugrians live in Western Siberia, along the river Ob and its tributaries: the Voguls live on the western, the Ostyaks on the eastern side, in an autonomous district of the Russian Federation. The Voguls number about 8,000, the Ostyaks about 21,000, but fewer and fewer of them still speak their own language. Those moving to towns often speak Russian, even to each other, and are abandoning their traditions. To some extent this is natural, for they cannot, for example, continue their traditional economy in towns, but we hope they can preserve their own language and at least some of their culture.

The traditional culture of Voguls is very similar to that of the Ostyaks, but as I did fieldwork only among the Ostyaks, I will write here only about them. There are about 1,000-1,500 families among them still following the traditional way of life based on hunting, fishing and food gathering; additionally they also keep reindeer. They live in a marshy territory, which means that among other deficiencies there is no electricity. They have to do everything by hand, from felling trees to cleaning reindeer skin and sewing clothing from it.

Living by hunting, fishing and food gathering means that a family needs quite a large territory. Traditionally they live in family groups of three or four generations, 10-20 members. The men hunt and fish, the women do all other kinds of work: they cook, sew, clean the houses (tents), wash, make smoke to repel mosquitoes, gather berries, smoke fish, chop firewood, etc. 
The families live quite far apart, so their contacts are not very close. This leads to the differentiation of the language: Eastern and Northern Ostyak is barely mutually intelligible, and there are significant differences even among Eastern Ostyak dialects. This is also seen in other fields of culture.

Visiting each other is not without difficulties, even in the case of neighbours. It is easier to travel in winter when the marsh is frozen over, and they can ride the reindeer sleigh. Guests spend weeks with their hosts, taking part in their life: the man goes to hunt and fish with his hosts, the woman helps her hostess.

The families living in the traditional way are nominally members of the Eastern Church, but in practice they keep their traditional polytheism. Ostyak mythology is about as complex as Greek mythology: there are gods and goddesses, spirits and idols. The beliefs of different Ostyak groups are also different: the names and roles of certain gods and goddesses may differ. The information published here about beliefs in the Surgut district comes from Agrafena Pesikova-Sopochina, Eastern Ostyak linguist and Leonid Mikhailovich Sopochin, Eastern Ostyak shaman. According to them the world is divided into seven spheres. The lowest is the underworld, the world of the dead: their ruler is the Prince of Illnesses. In this world everything is reversed. The second sphere is our domain, that of everyday people. The third is that of the gods and spirits. They did not tell us anything about the upper four spheres.

The main god, Numi Torum, has seven sons and seven daughters. One of the most important gods is his youngest son, the Watchman of the World. He is known and honoured by all Ostyaks. He is the mediator between gods and mankind. There are also local spirits taking care of a river or a forest. Besides this the families have their own idols.

Ordinary people cannot pass through the borders of the spheres: it is only the shaman who can do this. His task is to make contact with the gods of other spheres. With the help of the gods and spirits it is for him to say how to cure a sick person, where to look for a lost object, what to do in different situations etc.

Ostyak shamans are different to a certain extent from the shamans of other peoples. They are not born to be shamans, but they are chosen by the gods for this role. When someone is chosen, he begins to have dreams, from which he identifies his new task. It usually takes a long time, mostly years, to accept it: during this time the chosen person is ailing. When he decides to accept the task and to perform shaman ceremonies, he is cured. This was the case with Leonid Mikhailovich, too, who went from one hospital to another for six years. Being a shaman is not a job: the shaman lives from hunting and fishing like other Ostyaks.

While in Siberia in 1992 and 1993 we were able to observe a number of shaman ceremonies performed by Leonid Mikhailovich. During the ceremonies in Voki Rap Jagun $^{1}$ he did not wear any special clothing, apart from putting on his finest pair of boots made of reindeer skin. We also had to take off our rubber boots, and put on the best pair of shoes we had with us.

Leonid Mikhailovich usually played the drum without singing, but it also

1 'Small fox river': the name of the settlement where we were able to meet. 
happened that he sang during the ceremony. The aged head of the family in Voki Rap Jagun, Ivan Stepanovich Sopochin was considered to be one of the most powerful shamans. Unfortunately in 1992 he was already 82 years old and very weak: he died a year later. He was a singing shaman, and a number of his shaman songs recorded in 1974 can be found in the Novosibirsk Archive.

\section{Shaman songs}

The shaman ceremony is an important occasion for singing among the Eastern Ostyaks. Their way of singing differs fundamentally from that of European peoples. The function of the melody is to transmit human speech to the gods, who cannot hear ordinary speech. From this viewpoint clear intonation and exact rhythm is not significant. The pitches and intervals are unstable: it often happens, for example, that a third is either major, or minor in the very same melody. Besides this, within the same song at certain points of the melody we can hear several pitches.
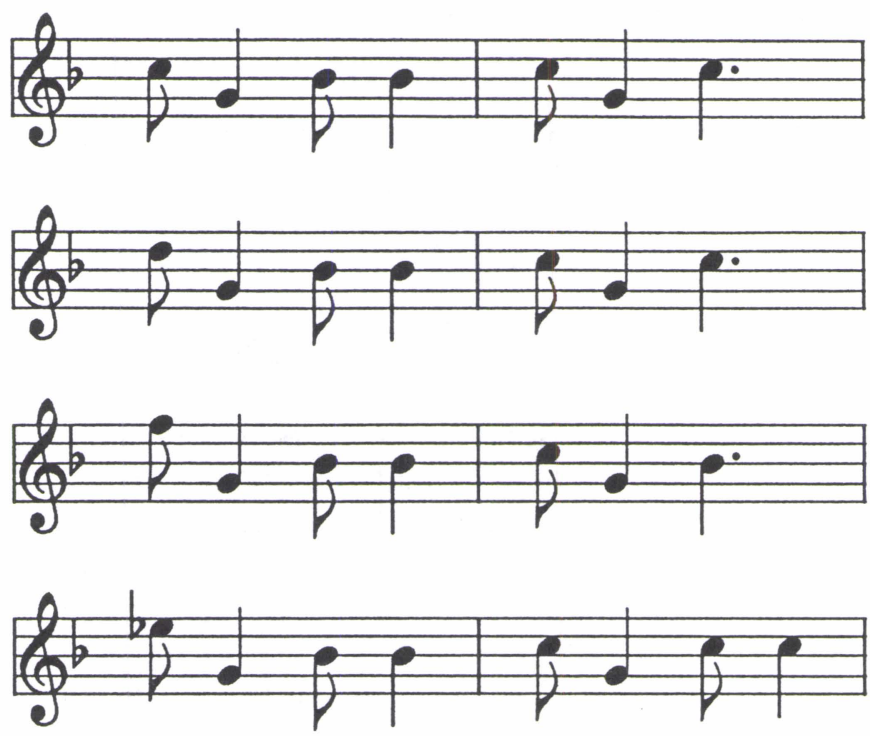

\section{Example 1.}

In the estimation of the local inhabitants, the singer performing a song in this way ('out of tune' in the European sense) is considered to be a good one if he knows a lot of texts, if he is able to sing long epic songs. This is usually characteristic of the shamans as well.

The situation is the same in the case of rhythm. The rhythmical pattern of a song is usually clear, but it often happens that a note is a little longer or shorter than it should be. Sometimes the singer coughs, sometimes makes a mistake and corrects 
it, and quite often takes a breath during a line, repeats the syllable and goes on. This is improper in Hungarian, but normal in Eastern Ostyak singing. When transcribing a song, we have to take into consideration what has to be marked and what is superfluous. Obviously the length of a break while the singer coughs or drinks some water has no musical significance; neither has the length of the erroneous syllable.

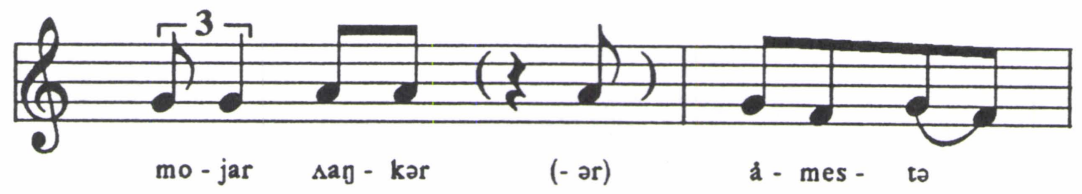

Example 2.

Unfortunately we cannot tell anything about the structure of the songs performed by Ivan Stepanovich, as the texts of these have not been written down, and for a number of reasons there is no way to reconstruct them. One reason is that because of the drum we cannot hear the texts clearly. Another is that the songs have their special language, frequently not comprehensible even by those speaking Ostyak as their mother tongue: for example there are inflected forms in them which are no longer used in everyday speech.

This is also the case with the songs of Ivan Stepanovich, recorded in 1974. His son, Yeremey Ivanovich Sopochin, copied some of his songs for us in 1992, and he willingly tried to help us to understand the texts. He could tell us the contents of the songs, but not the texts themselves, although he is a native speaker and the son of the singer. This makes our work very difficult, as we can study the songs only if we know both text and melody (Lázár 1988, 1994).

Fortunately the younger shaman, Leonid Mikhailovich Sopochin also sang us a number of long songs. The texts of these have been written down, so it is possible to study the construction of songs.

It was found that both the melody and the text of the songs are improvised, and neither of them is strophic. The basic unit of the melody is a motif (if it is half as long as a text-line) or a line (if it is as long as the text-line). Motifs are taken as basic melodic units only in those cases when they are joined together in different ways to form lines. A melody containing two kinds of motifs (a and $\mathbf{b}$ ), is considered to be one-seeded, if all the lines are constructed in the same way (ab).

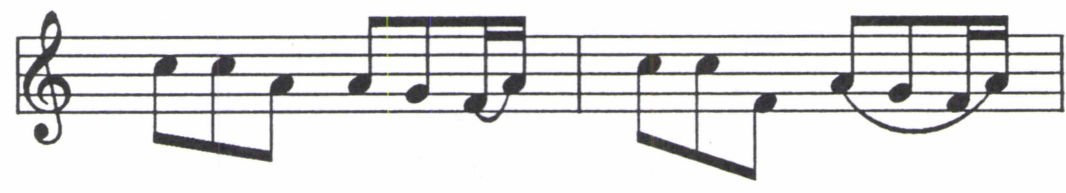

Example 3. 
50 - Lázár

4 motives from the 13 ones:
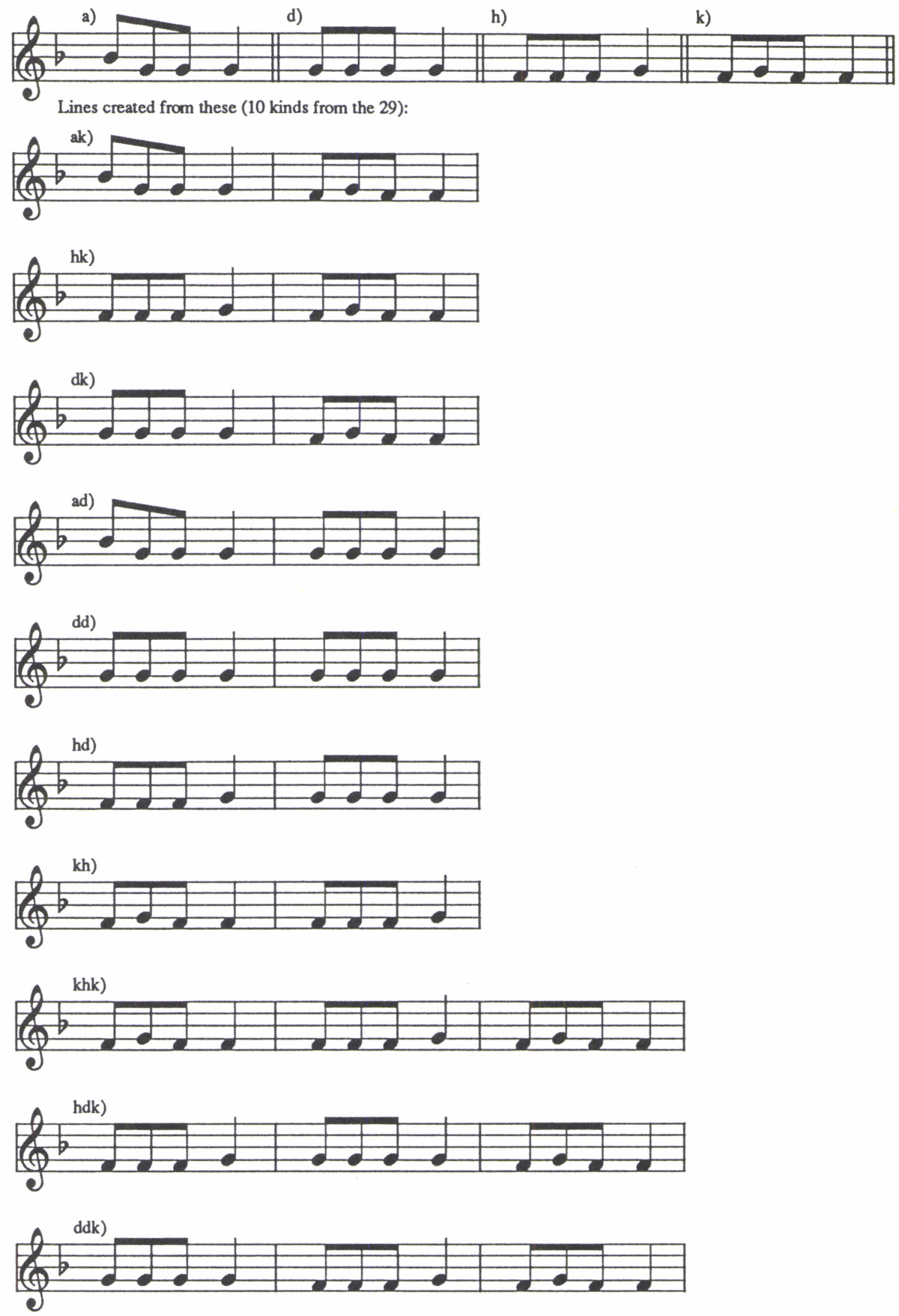

Example 4. 
If there are not only ab, but also bb lines in the melody, or even ba and perhaps even aa lines made from the motifs, it is considered to be a two-seeded melody, and the motifs are taken to be the basic units.

The larger melodic units in most cases are of different length, containing a different number of lines or motifs.

The texts are also improvised according to different rules, having units (sentences) of different length, which are different from the melodic units: the borders of the texts and melodies do not coincide. This is not a consequence of insufficient knowledge on the part of the singer; on the contrary, it is a principle of construction to make the song "endless". 


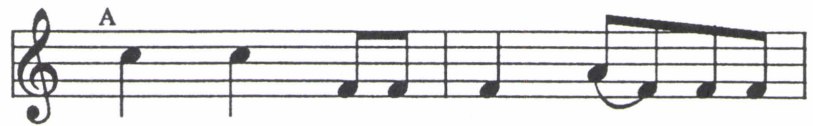

(... Good father of my daughter,)

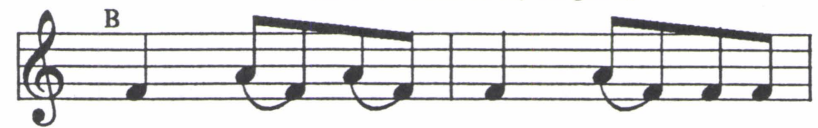

(good father of my child,)

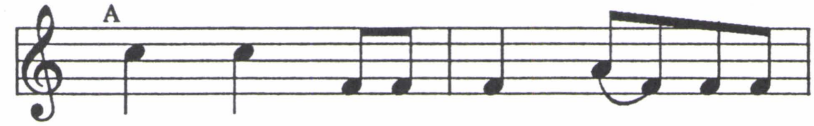

(you do foolishness,)

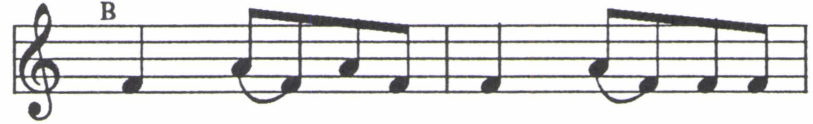

(the Russian fishing-net with dirty edge,)

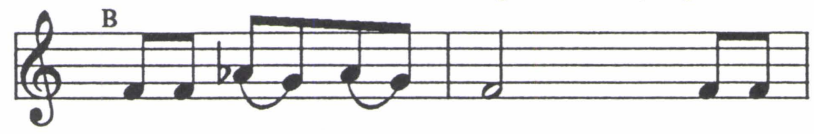

(how long do you pull?)

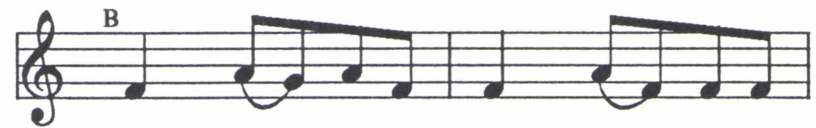

(Good father of my daughter,)

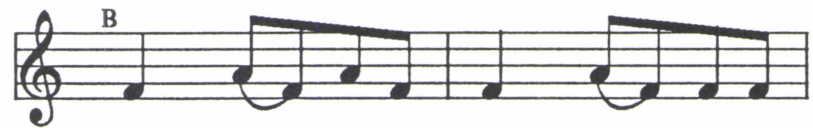

(good father of my child,)

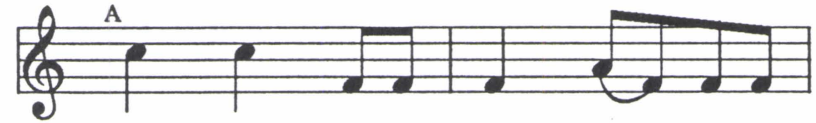

(you have been so well off?)

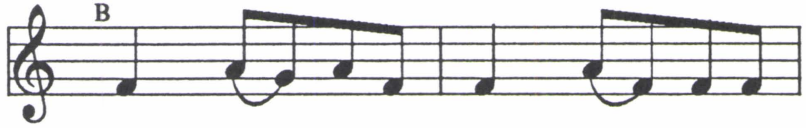

(Your body as white as the lake gull,)

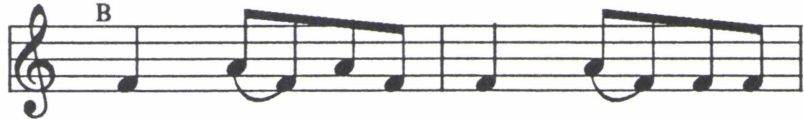

(you have been so well off,)

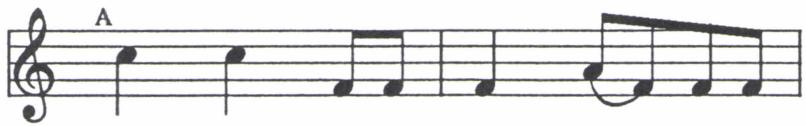

(you do foolishness!...)

\section{Example 5.}


If we consider improvising, we can see that this is a considerable mental achievement, though of course it is not done consciously; a good singer senses what he has to sing.

We need to know the way the songs are constructed if we want to find out how they can be learnt. It is not easy; the "student" has to know the stories, the poetic language which differs from everyday speech, the musical motifs or lines, he has to be able to construct the text, to construct the melody and to combine them. This is something much more difficult than to learn the text and melody of a Hungarian folk song, even if it is a ballad of 30 strophes. The young singers have to listen to the older ones a lot and to imitate them; in this way they can learn the stories, the language and the melody, and acquire a feel for the construction.

\section{Other song genres}

Besides shaman songs there are different kinds of bear songs and songs of invocation to gods and spirits. When guests arrive, the host offers a food sacrifice: bread, cakes, meat or fish, tea and some alcoholic drink are put on the table. The people stand in front of the table, the women, with shawls over their heads, bow and turn around several times. If the host is able to sing, he also sings a song of invocation to the gods and spirits. Then they eat the food and drink the alcoholic drink and tea.

Ostyaks also sing individual songs. These are sung in different situations of one's life: for example when travelling by boat for three or four days alone, the song is about the land where they are, or about family, relatives, and life events. There are also sung tales and tales with song insertions. The structural characteristics and the manner of performance are the same in these as in shaman songs: they are improvised and constructed in the same way, in these, too, we can find imprecise intonation, rhythmical irregularities, shorter and longer breaks due to improvisation or, for example, coughing, having no significance. Other songs, for example those with strophic structure, constant text and melody, sung in groups, indicate foreign influence. ${ }^{2}$

\section{Shamans and national identity}

More and more Ostyaks are having to move to villages or towns where they cannot preserve their traditional way of life. They cannot hunt and fish, they cannot fell trees to make a fire, but they have to earn money with some kind of unfamiliar work. They cannot keep the rules of taiga or tundra life but have to learn other rules. In towns they live mainly among Russians. Many of them live in mixed families, marrying someone of another nationality, and their children no longer speak Ostyak

\footnotetext{
${ }^{2}$ Lázár 1999.
} 
and cannot talk to their own grandfathers. They try to assimilate into the village or town population, speak Russian even with each other, and sing Russian songs (if any). This means that they lose touch with their roots, and very often relieve the ensuing tension by drinking.

It is clear that as town-dwellers Ostyaks cannot live by hunting and fishing, but they can try to retain their identity among these different circumstances as well, by keeping their spiritual culture: this helps to preserve the national identity. Shamanism is very important in the spiritual culture of the Ostyaks, it sums up how they perceive the world. A shaman ceremony is much more than the text and the melody of the song and the movements of the dance performed during it.

However attractive, rich and colourful this poetic world may be, it is to be feared that there are fewer and fewer people knowing this culture and able to preserve their roots, their national identity. I am convinced that there is a place for shaman poetry in the culture of our days, too: this can be seen also from the popularity of the poems of Yuvan Shestalov, the most famous Vogul poet. I am convinced that co-operation and mutual help is very important in our world and in our days, too, when we have so many problems with the evils of urbanism, isolation and alienation. Ostyak shamans may have an important role in keeping together at least that part of their people who speak their own language and accept their Ostyak identity. They are honoured people thoroughly familiar with their culture, and hopefully they have the spiritual strength for this task. We, researchers also try to do our best to help them in this, and we can only hope that our efforts are not in vain.

\section{Literature}

Lázár, Katalin 1988. Structure and Variation in Ob-Ugrian Folk Music. Studia Musicologica Academiae Scientiarum Hungaricae 30. 248-296. Budapest

Lázár, Katalin 1994. Some Problems of Notating and Analysing Ostyak Folk Melodies. Explorations in Finnish and Hungarian Folk Music and Dance Research, vol. I. 112-122. Kaustinen

Lázár, Katalin 1999. Influences of Other People's Music on Eastern Ostyak Folk Songs. New Countries, Old Sounds? Munich, 1999. 91-98. 